\title{
ABORDANDO ITINERÁRIOS DE ATIVISTAS A PARTIR DA SOCIOLOGIA DAS CARREIRAS MILITANTES
}

\section{Brena Costa Lerbach ${ }^{1}$}

\section{INTRODUÇÃ̃}

A questão da abordagem da ação individual nos fenômenos políticos tem se consolidado como tema de discussão na Ciência Política. Se, de um lado, alguns estudiosos enfatizaram a ação individual - seja a partir de uma perspectiva psicologizante, seja a partir do paradigma da escolha racional -, de outro, outros analistas focaram em fatores estruturais externos, recorrendo, por exemplo, a determinantes estruturais, como classe social, e a conceitos como oportunidades políticas, redes, frames, etc. Como resultado deste debate, vários autores têm chamado a atenção para a necessidade de superar certa dificuldade no que diz respeito à integração entre agência humana e estrutura na compreensão de relações e processos políticos, argumentando que os pesquisadores do ativismo e dos movimentos sociais precisam revisitar o papel dos indivíduos nesses processos e nos resultados por eles alcançados (MISCHE, 2008; MORRIS e STAGGENBORG, 2004; MORRIS, 2000).

Diante desse quadro, o presente artigo objetiva propor um instrumental teórico útil ao estudo de trajetórias individuais de ativistas. Para tanto, apresenta os principais pressupostos sob os quais se assenta a sociologie des carrières militantes (FILLIEULE,

\footnotetext{
${ }^{1}$ Mestranda em Ciências Sociais na Universidade Federal do Espírito Santo. Possui graduação (bacharelado e licenciatura plena) em Ciências Sociais pela mesma instituição. Contato: brenalerbach@gmail.com
}

Em Tese, Florianópolis, v. 11, n. 2, jul./dez., 2014. ISSN: 1806-5023 
2010, 2013) - abordagem teórica que se fundamenta no conceito de carreira militante ${ }^{2}$; além de outros elementos e conceitos que podem ser utilizados de maneira articulada com o que propõe esta abordagem, como o conceito de esferas de vida, e as implicações do campo político, das experiências sociais e das socializações secundárias sobre os itinerários políticos individuais.

Partindo de uma compreensão da militância como atividade social individual e dinâmica, a sociologia das carreiras militantes proposta por Olivier Fillieule (ibidem) sugere a construção de um modelo para analisar o engajamento individual e sua evolução temporal, colocando-o em relação com variáveis contextuais e situacionais. Assim, recorre ao conceito de carreira, desenvolvido pelos interacionistas simbólicos. Aplicada ao engajamento político, a concepção de carreira permite compreender, entre outras coisas, como, em cada etapa da biografia, as atitudes e comportamentos individuais são condicionados por envolvimentos anteriores, colocando também a esfera do ativismo em relação com as outras esferas de vida (profissional, familiar, etc.) do indivíduo, de maneira a contextualizar sua atuação política ao longo do curso de vida. Por acreditarmos que esta abordagem teórica ofereça instrumentos adequados para o estudo de trajetórias de ativistas, apresentaremos neste artigo de forma combinada com outros conceitos também úteis à compreensão de fenômenos ligados à temática do ativismo e do engajamento político.

O artigo segue dividido em três partes. A primeira parte faz uma apresentação da sociologia das carreiras militantes - de seus principais conceitos e dos procedimentos analíticos implicados. Na segunda parte, falaremos sobre o conceito de esferas de vida (PASSY e GIUGNI, 2000), que, em suas dimensões objetiva e subjetiva, enfatiza processos de formação de redes e de percepções individuais; e possibilita pensar o ativismo em relação às demais áreas da vida. Na terceira parte, trataremos do papel do campo político, das experiências pessoais e das socializações secundárias (GAXIE, 2002) - em especial as que acontecem dentro das organizações (FILLIEULE, 2010;

\footnotetext{
${ }^{2}$ Ou carreira ativista. Nos textos de Fillieule publicados em inglês o termo é activist career, enquanto nas versões em idioma francês é carrière militante.
}

Em Tese, Florianópolis, v. 11, n. 2, jul./dez., 2014. ISSN: 1806-5023 
MISCHE, 2008) - na definição de posições individuais em relação à política durante a vida. Finalizaremos com algumas considerações, buscando, sinteticamente, retomar e articular os elementos e conceitos trabalhados.

\section{A SOCIOLOGIA DAS CARREIRAS MILITANTES}

A noção de carreira militante foi desenvolvida a partir do interacionismo simbólico e, de acordo com Fillieule (2010), constitui um "paradigma interacionista renovado" nos estudos sobre os movimentos sociais. O autor define o interacionismo simbólico como uma abordagem microssociológica e processual que sistematicamente liga o indivíduo e o estudo de situações a fatores contextuais mais amplos e a normas e ordens sociais. Trata-se de uma perspectiva em que indivíduos e sociedade não apenas são interdependentes, como também se constroem mutuamente. Como apontado pelo autor, tal abordagem possibilita a compreensão de comportamentos de atores políticos, assim como processos de engajamento e de desengajamento, permitindo tratar questões: de predisposição para a operacionalização do ativismo, de diferenciadas formas de ativismo ao longo do tempo, da multiplicidade de engajamentos ao longo do curso de vida, do abandono ou da extensão do comprometimento, etc.

O conceito de carreira militante advém dos trabalhos de Everett Hughes, Howard Becker, Hans Gerth e Charles Wright Mills, e Anselm Strauss. Em uma citação de Becker, na qual o autor faz uma referência literal a Hughes, o conceito de carreira é dividido em duas dimensões, expressando bem alguns dos pressupostos iniciais em que se assenta a sociologia das carreiras militantes proposta por Fillieule:

Em sua dimensão objetiva, uma carreira é "uma série de novos status e ofícios definidos claramente... típicas sequências de posição, realizações, responsabilidade, e mesmo de aventura... Subjetivamente, uma carreira é a perspectiva em movimento na qual a pessoa vê sua vida como um todo e interpreta o significado de seus vários atributos, ações e as coisas que 


\title{
$1 \mathbf{C S E} \mid \begin{aligned} & \text { Revista Eletrônica } \\ & \text { dos Pós Graduandos } \\ & \text { em Sociologia Política } \\ & \text { da UFSC }\end{aligned}$
}

acontecem com ele" (HUGHES, 1937, p. 409-410 in BECKER, 1966, p. 102 apud FILLIEULE, 2010: 4).

O conceito de carreira nos permite focar nos processos e numa dialética permanente entre a história individual, as instituições sociais e o contexto; e seu procedimento metodológico fundamental consiste na reconstrução da sequência de passos e de mudanças no comportamento e na perspectiva dos indivíduos estudados. A explanação de cada passo ou etapa da carreira de alguém seria, então, algo importante para a compreensão do comportamento resultante, uma vez que são compreendidos como fatores causais dos comportamentos adotados (BECKER, 1966 apud FILLIEULE, ibidem). Ao abordar a trajetória de um indivíduo levando em consideração as relações e mudanças produzidas em contato com diferentes contextos e instituições, etapa por etapa, uma análise construída sob essa perspectiva de carreira combina movimentos sincrônicos e diacrônicos:

\begin{abstract}
Uma abordagem de carreira consequentemente envolve considerar as duas dimensões essenciais da identidade social: de uma perspectiva diacrônica, a transformação de identidades e os mecanismos sociais operantes nessas transformações; e de uma perspectiva sincrônica, a pluralidade de lugares nos quais os atores sociais devem estar envolvidos (FILLIEULE, 2010: 4 itálicos no original $)^{4}$.
\end{abstract}

Assim, a compreensão das transformações objetivas e subjetivas pelas quais os indivíduos passam ao longo de sua carreira envolve o exame conjunto de ambos os movimentos. Na mesma linha, Strauss (1959 apud FILLIEULE, ibidem) analisa a forma como as identidades estão sujeitas a mudanças permanentes, tendo em vista a

\footnotetext{
${ }^{3}$ Original em inglês: "In its objective dimension, a career is 'a series of statuses and clearly defined offices... typical sequences of position, achievement, responsability, and even of adventure... Subjectively, a carrer is the moving perspective in which the person sees his life as a whole and interprets the meaning of his various attributes, actions and the things which happen to him"'.

${ }^{4}$ Original em inglês: "A career approach consequently involves considering the two essential dimensions of social identity: from a diachronic perspective, the transformation of identities and the social mechanisms at work in these transformations; and from a synchronic perspective, the plurality of sites in which social actors may be involved".
} 
modificação da estrutura social e das posições sucessivas ocupadas pelos atores, o que significa que é preciso atentar para os diferentes estágios na biografia do ator e para os termos em que a interpretação subjetiva de tais mudanças é experienciada. Nesse sentido, Strauss distingue entre "mudanças institucionalizadas" (ex.: casamento, entrada no mundo do trabalho) e "acidentes biográficos" (ex.: crises, perdas, fracassos, etc.), sublinhando as mudanças de identidade provocadas.

Outro ponto que ganha destaque no estudo das carreiras militantes é a existência de uma pluralidade de mundos sociais ou esferas de vida nas quais os ativistas estão inseridos (STRAUSS, 1959, MEAD, 1934 apud FILLIEULE, 2010). Como Fillieule aponta, tal situação faz com que os indivíduos estejam permanentemente sujeitos à obrigação de se submeterem a diferentes normas, regras e lógicas, que podem eventualmente entrar em conflito. O tópico seguinte trará algumas formulações sobre o assunto, tendo em vista a importância dessas considerações para a compreensão das carreiras de ativistas em correlação com os itinerários e relações construídas em outros campos da vida.

\section{RELAÇÕES ENTRE AS DIFERENTES ESFERAS DE VIDA E SUAS IMPLICAÇÕES PARA O ENGAJAMENTO OU O DESENGAJAMENTO DE ATIVISTAS}

Florence Passy e Marco Giugni (2000) também empregam elementos interacionistas para tratar da participação individual em movimentos sociais. Para os autores, a participação política, como qualquer outra atividade social, possui um significado específico na vida dos ativistas, que pode ser estruturado a partir do que eles propõem chamar de esferas de vida: “A vida de cada um de nós é composta de esferas de vida, que podem ser definidas como 'regiões' distintas embora relacionadas na vida de um indivíduo, cada uma com suas próprias bordas, lógica e dinâmica" (ibidem:

Em Tese, Florianópolis, v. 11, n. 2, jul./dez., 2014. ISSN: 1806-5023 
121). ${ }^{5}$ De maneira semelhante ao conceito de carreira, desenvolvem um conceito de esfera de vida assentado em uma dimensão objetiva e em uma dimensão subjetiva:

\begin{abstract}
Uma esfera de vida tem ambos um lado objetivo e um lado subjetivo. Seu lado objetivo é representado pelo pertencimento individual a um grupo e pelas relações sociais que emergem deste pertencimento. $\mathrm{O}$ conceito de redes sociais, como tem sido usado na literatura sobre movimentos sociais, captura muito desse aspecto das esferas de vida. Entretanto, a importância heurística do conceito de esferas de vida reside em seu lado subjetivo, que reflete a percepção que os atores sociais têm da sua imersão em grupos ou redes (PASSY e GIUGNI, 2000: 121) ${ }^{6}$.
\end{abstract}

Passy e Giugni explicam que o conceito de esferas de vida envolve dois elementos cruciais. $\mathrm{O}$ primeiro diz respeito às percepções individuais da realidade. Sua importância reside no fato de desdobrar o significado que objetos e ações têm para os indivíduos, explicitando a maneira como as experiências são significadas. Para clarificar o argumento, utilizam o conceito de self-interaction proposto por Blumer:

\begin{abstract}
De acordo com esta perspectiva teórica, os atores sociais interagem através de significados, então estabelecendo um enquadramento cognitivo da realidade que é constantemente redefinido e transformado como resultado de cadeias de interação (BLUMER, 1969). Os significados canalizam interações sociais que, em troca, transformam a estrutura de significados. Entretanto, as interações não estão apenas situadas no nível coletivo, mas também no nível individual. Isso quer dizer que os atores também interagem e se comunicam com eles mesmos. Blumer (1969) nomeou esse processo de self-interaction (PASSY e GIUGNI, 2000: 123 - itálico no original) ${ }^{7}$.
\end{abstract}

\footnotetext{
${ }^{5}$ Original em inglês: "The life of each of us is composed of life-spheres, which can be defined as distinct though interrelated 'regions' in the life of an individual, each one with its own borders, logic and dynamic".

${ }^{6}$ Original em inglês: "A life-sphere has both an objective and a subjective side. Its objective side is represented by the individual's belonging to a group and the social relations arising from such belonging. The concept of social networks, as it has been used in the social movement literature, captures much of this aspect of life-spheres. However, the heuristic importance of the concept of life-spheres lies in their subjective side, which reflects the perception social actors have of their embeddedness in groups or networks".

${ }^{7}$ Original em inglês: "According to this theoretical perspective, social actors interact through meanings, thus establishing a cognitive frame of reality that is constantly redefined and transformed as a result of chains of interaction (Blumer, 1969). Meanings channel interactions that, in turn, transform the structure
} 
Segundo essa concepção, o comportamento humano é mediado por um processo de interpretação baseado em interações sociais e em interações com o próprio self, que ajudam os indivíduos a dar significado à realidade social e a agir de forma apropriada. A interação é factual e simbólica, e a decisão de se engajar ou de abandonar a militância depende dos dois tipos de interação e de sua relação mútua. Por sua vez, as redes de interação estão ligadas às esferas de vida do indivíduo: a inserção em redes influencia a orientação das esferas de vida, e as interações cotidianas diárias ajudam na construção do self; enquanto, de outro lado, as esferas de vida definem e redefinem as redes por meio do processo de self-interaction.

O segundo elemento consiste na ideia de que, apesar de apresentarem fronteiras e códigos específicos, as esferas de vida encontram-se interconectadas e em constante interação. Os autores argumentam que é precisamente essa interação que modela as estruturas de significados dos atores, entendendo que o mundo subjetivo dos sujeitos é formado pelas esferas de vida e por sua interação mútua.

Entre as esferas de vida mencionadas estão as esferas do trabalho, da família, das amizades, dos estudos, da ação política, etc. As esferas não possuem pesos iguais na vida de uma pessoa, sendo que uma esfera será mais importante quanto mais for ativada. Passy e Giugni sustentam que a hierarquia das esferas muda de acordo com o momento no curso de vida, mas que, em geral, família, estudos e trabalho permanecem como as esferas mais relevantes nas sociedades ocidentais, impactando as estruturas de significados de ativistas no que diz respeito ao ativismo político de forma positiva ou negativa. A partir dessas considerações, os autores trabalham com a hipótese de que, quanto mais conectadas as esferas centrais na vida de um ativista com a esfera do engajamento político, mais estável tende a ser o seu comprometimento com o movimento e com a causa. Por outro lado, a falta de ligação das esferas de vida com a esfera do ativismo, em muitos casos relacionada a um avanço no ciclo de vida, levaria o sujeito a diminuir ou abandonar o envolvimento em movimentos sociais.

of meanings. However, interactions are not only located on the collective level, but also in the individual level. That is to say, actors also interact and communicate with themselves. Blumer (1969) has named this process self-interaction". 


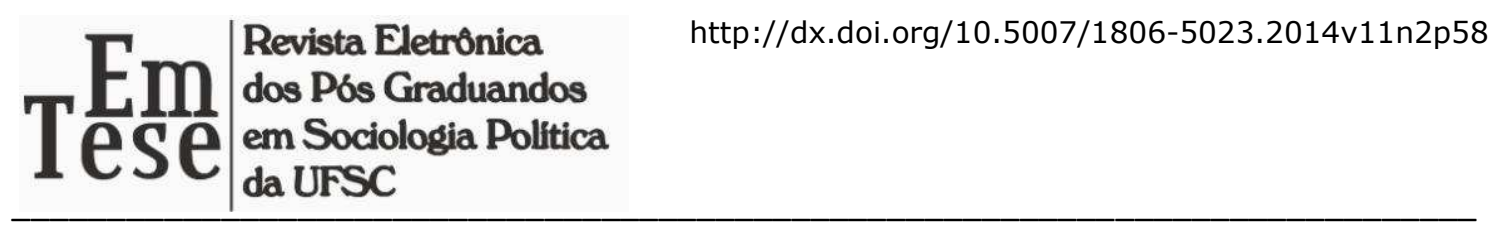

Assim, em uma síntese dos dois elementos, os autores apontam que "ambas redes sociais e esferas de vida contribuem para a definição da estrutura de significado dos indivíduos durante o curso de suas vidas" (PASSY e GIUGNI, ibidem: 125$)^{8}$.

Algumas pesquisas dão exemplos de como as relações entre esferas podem facilitar e sustentar o ativismo ou, ao contrário, promover seu enfraquecimento, levando, em alguns casos, ao desengajamento. Em um estudo sobre militância e vida cotidiana, Bernadete Baltazar (1998) chama a atenção para a frequente alegação, por parte de lideranças de movimentos populares, de dificuldades para conciliar militância e vida pessoal. Apesar de a autora sublinhar que bem-estar coletivo e prazer individual não são dicotômicos ${ }^{9}$, muitas lideranças relataram haver conflito entre os projetos de vida e a militância. Dessa forma, muitos lamentaram não poder se dedicar a outras esferas de vida, como à família, à carreira profissional e aos estudos. Ao contarem casos de pessoas que romperam com o ativismo para investir na carreira profissional, por exemplo, esta opção foi descrita pelos entrevistados como ir "cuidar da própria vida" expressando, nesse sentido, uma competição que outras esferas de vida mantêm constantemente com a esfera do ativismo político.

Seguindo esta linha, Rebecca E. Klatch (2000) realiza um estudo sobre como, em momentos posteriores do ciclo de vida, os mundos do trabalho e da família afetaram o engajamento de jovens ativistas estadunidenses atuantes na década de 1960. Os resultados mostraram que, a depender da orientação assumida dentro dessas esferas, família e trabalho podem tanto cultivar e confirmar crenças e um engajamento político, quanto retirar as pessoas do mundo do ativismo. Assim, confirmando a hipótese de Passy e Giugni, a sustentação do engajamento mostrou-se mais viável naqueles casos

\footnotetext{
${ }^{8}$ Original em inglês: "both social networks ans life-spheres contribute to the definition of the individual's structure of meanings during the course of their lives".

$9 \mathrm{Na}$ verdade, de acordo com Gaxie (1977, 2005), a atividade militante é caracterizada por gerar retribuições (principalmente simbólicas: prazer, convívio, felicidades, honra, gratificações, prestígio, admiração) que estimulam a renovação do ativismo, no entanto as gratificações associadas a esse investimento competem com aquelas que podem ser obtidas em outras esferas da vida (amorosa, profissional, familiar, etc.). Segundo o autor, os sacrifícios e riscos corridos são inclusive valorizados dentro do universo militante, que enaltece o desinteresse, a doação, o altruísmo, a gratuidade e a generosidade.
} 
em que foi observada proximidade entre as esferas da família e do trabalho e a esfera do ativismo, por exemplo, quando ativistas se casaram com outros ativistas e quando as profissões escolhidas tinham relação com a política ou com a causa defendida. Por outro lado, quando os ativistas se empregaram em áreas não relacionadas ou pouco coerentes com suas crenças e valores, a esfera do trabalho passou a concorrer e, em alguns casos, a conflitar com as antigas posições como militantes. No que diz respeito à família, a existência de filhos e a opção por uma família convencional também contribuíram como fatores para uma mudança de prioridades, dificultando a manutenção do engajamento ou mesmo levando deliberadamente ao desengajamento. Viu-se, com isso, que na vida adulta a esfera do ativismo político passou a competir com mais força com as esferas do trabalho e da família.

É fundamental ressaltar que o pertencimento a uma pluralidade de mundos sociais, redes e esferas de vida - e mudanças nesses pertencimentos ao longo do tempo - faz com que os indivíduos sejam governados por princípios heterogêneos e, muitas vezes, contraditórios. Cada ator incorpora uma multiplicidade de padrões comportamentais, orientações e hábitos que lhes guiam a ação e que sofrem transformações ao longo da vida (FILLIEULE, 2010), e cabe atentar para os impactos que a inserção em novas redes e mundos sociais pode produzir sobre as carreiras ativistas. Nesse sentido, temos chamado a atenção (LERBACH, 2014) para a entrada e atuação de ativistas em órgãos públicos ${ }^{10}$ : situação em que passam a desempenhar a esfera profissional no Estado - o que acaba gerando impactos sobre a carreira ativista, dadas as implicações políticas desta mudança no lugar de atuação (situação em que se vai da "sociedade civil" para o "Estado", ou de "desafiantes" a "membros da polity"). Os resultados de nossas pesquisas revelam impactos variáveis: em alguns casos há desengajamento em relação ao ativismo (casos em que passam a atuar unicamente como gestores e técnicos nos órgãos, assumindo-se e colocando-se a partir desse papel); em outros, há o desenvolvimento de uma postura mais favorável a parcerias entre movimento e Estado por parte dos que permanecem militantes (e que em geral

\footnotetext{
${ }^{10}$ Os impactos da passagem por organizações sobre os indivíduos ainda serão discutidos em linhas gerais na próxima seção, quando falaremos sobre socialização secundária.
} 
enfatizam o desejo de "gerar uma contribuição" dentro das agências do poder público); e, ainda, mostra-se recorrente certa manifestação de contradições, havendo os que afirmam continuar "ativistas" da causa, mas que se afastaram da atuação em movimentos e entidades, produzindo críticas em relação a esta modalidade de atuação política. Outro ponto que interessa ressaltar diz respeito às dificuldades de conciliação, para aqueles que se mantiveram ativistas, entre as esferas ativista e profissional, sendo que frequentemente falam sobre o desafio de manterem a "coerência" entre a atuação em ambos os campos e o cuidado para não "caírem em contradição" - expressando, dessa maneira, que a ocupação de cargos no Estado por ativistas é permeada por tensões ${ }^{11}$.

Já falamos sobre o conceito de carreira militante, sobre o papel das interações nos processos de significação individual e sobre como a esfera do ativismo político deve ser compreendida em relação com outras esferas ou áreas da vida. Com o intuito de dar sequência à reunião de elementos para o estudo de trajetórias de ativistas, prosseguiremos no próximo tópico tratando de processos por meio dos quais preferências, perspectivas e comportamentos individuais são configurados.

\section{O PAPEL DO CAMPO POLÍTICO, DAS EXPERIÊNCIAS SOCIAIS E DA SOCIALIZAÇÃO SECUNDÁRIA NA FORMAÇÃO DE PREFERENCIAS, COMPORTAMENTOS E PERSPECTIVAS INDIVIDUAIS}

A ação individual não pode ser compreendida de forma apartada dos meios sociais e das instituições nas quais cada um encontra-se inserido. Como a perspectiva interacionista busca ressaltar, para compreender comportamentos e posições individuais é preciso dar relevo às interações que os indivíduos desenvolvem com instituições e

\footnotetext{
${ }^{11}$ Estas informações consistem em dados preliminares de minha dissertação de mestrado, que trata da inserção de ativistas ambientais no Estado e se encontra em processo de elaboração.
}

Em Tese, Florianópolis, v. 11, n. 2, jul./dez., 2014. ISSN: 1806-5023 
estruturas sociais dentro de determinados contextos e ao longo do tempo. De acordo com Fillieule (2010), deve-se levar em consideração três níveis inter-relacionados: o nível macro do campo político expandido, o nível micro das biografias e o nível médio das organizações. São estas inter-relações que informam a opção por diferentes preferências, por certas atitudes e não outras, e a construção das perspectivas individuais. Nesse sentido, cabe destacar o papel de campo político mais amplo, as experiências sociais e a socialização secundária - principalmente aquela que acontece dentro das organizações sociais -, exercem sobre as visões e posições sustentadas pelos indivíduos enquanto atores políticos.

O campo político, que varia de acordo com contextos e situações específicas, apresenta configurações e valores sociais diferentes, impactando as formas como, por exemplo, cidadania, participação política e ativismo são encarados. Algumas atitudes e envolvimentos podem ser valorizados, enquanto outros podem ser desestimulados. Assim, quando Mische (2008) analisa o ativismo de diferentes gerações de jovens no Brasil no contexto de abertura e redemocratização política, observa que, enquanto os jovens que tinham iniciado seu engajamento nas décadas de 1970 e 1980 costumavam combinar o ativismo com a militância político-partidária, os que começaram o ativismo durante e depois do impeachment do presidente Fernando Collor de Mello (1992) tinham um entendimento diferente a respeito das relações entre a participação cívica e a partidária, desenvolvendo um ativismo mais especializado, cultural e profissional, sem tanta interseção com os partidos. Aliados a outros fatores, como a inserção em redes e o envolvimento com múltiplos grupos organizados, os diferentes momentos desse ambiente de mudança política impactaram a forma como os jovens viram suas "vidas em formação" e as maneiras como eles se uniram a outros jovens para tentar interferir naquele ambiente. Isso repercutiu sobre os perfis e carreiras dos ativistas, assim como sobre as interações entre atores formados em diferentes gerações dentro deste período, levando a uma comunicação tensa nos públicos observados. Como expressão dessa dificuldade, a autora ressalta que as lideranças mais antigas eram acusadas de 


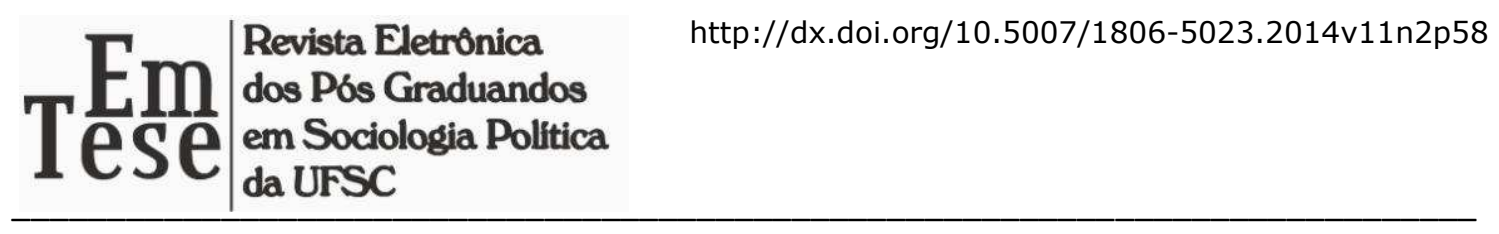

partidarismo, levando a divisões internas na União Nacional dos Estudantes - UNE depois de 1992.

As diferentes experiências sociais pelas quais os indivíduos passam ao longo da vida e os processos de socialização resultantes dessa vivência também condicionam e exercem influência sobre o relacionamento com a política, os investimentos e as preferências individuais. A questão é abordada por Daniel Gaxie (2002) num estudo onde ele associa o nível de envolvimento com o campo político e as preferências sustentadas nesse domínio com as socializações pelas quais os indivíduos passam ao longo da vida. Socialização é definida pelo autor como a interiorização, pelo indivíduo, de aspectos da sociedade e dos setores sociais onde se localiza. Essa interiorização se apresenta na aprendizagem de maneiras de ser, pensar e agir mais ou menos adaptadas às posições ocupadas pelos indivíduos; e acontece por meio de diversos processos, como os de educação (explícita ou difusa), transmissão, imitação, adaptação ou inovação. Além da socialização primária, que acontece na infância e tem como principais meios sociais a família e a escola, há a socialização secundária, que consiste nos processos de aprendizagem ulteriores que se desenvolvem ao longo da vida, orientando e reorientando as trajetórias pessoais:

As socializações secundárias são o resultado da trajetória biográfica, que podem ser, por exemplo, ascendentes ou declinantes, de pertencimento a diversos meios (conjugal, familiares, profissionais, de amizades, culturais, comunitários, confessionais, associativos, sindicais, de vizinhança ou outros) e das posições ocupadas no espaço social e as divisões do trabalho (notadamente entre os sexos, as gerações, as categorias sociais) (ibidem: $148)^{12}$.

Mudanças nas posições (ascensão ou declínio social, alteração do estado civil, mudança de emprego, o início de um curso numa faculdade, por exemplo) podem levar

\footnotetext{
${ }^{12}$ Original em francês: "Les socialisations secondaires sont le résultat de la trajectoire biographique, qui peut être, par example, ascendante ou declinante, de l'appartenance à divers milieux (conjugal, familiaux, professionels, amicaux, culturels, communautaires, confessionels, associatifs, syndicaux, de voisinage ou autres) et des positions occupées dans l'espace social et les divisions du travail (notamment entre les sexes, les générations, les catégories sociales)".
} 
a mudanças nos pontos de vista, e os efeitos da socialização podem ser congruentes ou contraditórios em relação às posições ocupadas. O autor assinala que as experiências anteriores podem frear ou entravar as mudanças, que podem ser dolorosas e acompanhadas de um sentimento de culpa: "Para qualquer um relativamente preocupado com a política, a ruptura com opiniões passadas altamente valorizadas é custosa" (GAXIE, 2002: 163) ${ }^{13}$. Para ilustrar, mencionaremos aqui dois dos casos analisados por Gaxie. O primeiro diz repeito ao caso de uma mulher de 50 anos que, tendo a vida inteira manifestado uma orientação política à direita (e com família e marido também seguindo fortemente esta linha), ao começar a estudar em uma universidade marcada por influências de esquerda, começou a modificar seu olhar e seus valores políticos. Esta nova situação entrou em contradição com a formação política anterior, e, quando ainda optava por um candidato de direita, alegou que votava "um pouco contra si mesma". Essa mudança de orientação coincidiu também com a degradação de seu casamento, uma vez que ela e o marido passaram a discordar sobre uma série de questões, o que contribuiu para seu divórcio e culminou na ruptura de sua fidelidade em relação à direita política. O segundo caso relata as mudanças nas preferências políticas de outra mulher, também com 50 anos. Nascida em uma família de imigrantes judeus de esquerda, a política teve lugar especial ao longo de sua trajetória pessoal, tendo ela participado de organizações estudantis judias, das mobilizações estudantis de 1968 na França e se engajado na luta feminista. Contudo, ao casar-se com jornalista televisivo com posses, ela, que era professora, elevou seu patamar financeiro e passou a estar em contato com personalidades e pessoas de classes mais altas. Vivendo esta nova realidade e um tanto desiludida com as experiências da esquerda no poder, passou a votar na direita - algo que, segundo ela, não a deixou contente, fazendo com que sentisse que estava "traindo a si mesma". Avaliou, ao final, que teria se tornado "um pouco burguesa", tendo em vista que passou a votar pensando em defender seus bens e pagar menos impostos.

\footnotetext{
${ }^{13}$ Original em francês: "Pour quelq'un de relativement concerné par la politique, la rupture avec des opinions passées hautement valorisées est coûteuse".
} 


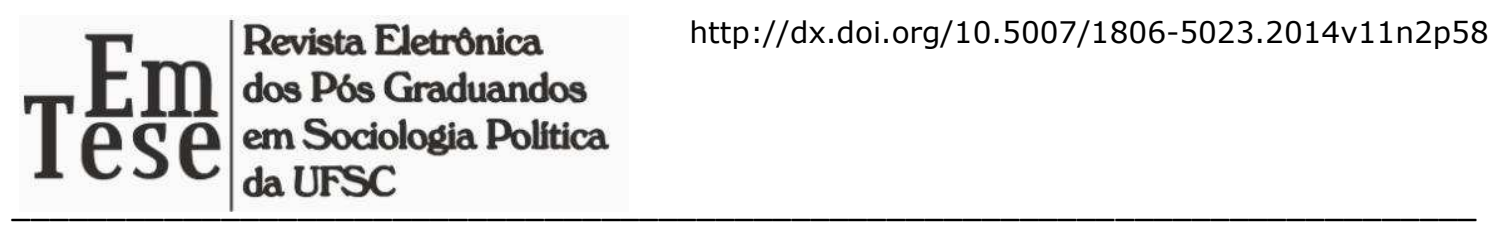

Assim, observa-se que as transformações nas perspectivas e preferências individuais podem ser acompanhadas por sentimentos de resistência, e que a síntese dessas influências múltiplas pode conter aspectos contraditórios. A pesquisa de Gaxie conclui que, em se tratando da relação com a política, os efeitos da socialização secundária parecem prevalecer sobre os da socialização primária; que o pertencimento a universos sociais afastados ou opostos pode acompanhar diversas formas de instabilidade, hesitação e ecletismo; e que essas mudanças são permanentes e consistem num processo que se desenrola de forma constante ao longo da vida:

\begin{abstract}
Os instrumentos de apreensão das realidades políticas (e também das outras realidades sociais) são então suscetíveis de serem adquiridos ao longo da vida, e a relação com a política (e, de forma mais geral, com o mundo social) pode assim variar ao longo de cada história biográfica. A socialização deve então ser analisada como um processo global coextensivo a cada história de vida (ibidem: 170$)^{14}$.
\end{abstract}

As experiências adquiridas através do pertencimento a uma categoria social ou a ocupação de uma posição dentro do mundo social são, então, para o autor, frequentemente decisivas na orientação das maneiras como os indivíduos veem e se posicionam em relação à realidade, em especial, em relação aos assuntos políticos.

Uma importante instância de socialização para aqueles envolvidos com o mundo da política são as organizações políticas e sociais. Nesse sentido, Fillieule (2010) chama a atenção para a necessidade de abordar os processos pelos quais as organizações estruturalmente, socialmente e politicamente selecionam e orientam as atividades desempenhadas pelos indivíduos. O autor toma como referência algumas proposições de Gerth e Wright Mills (1964 apud ibidem), que, ao examinarem as relações entre indivíduos e instituições, destacam a existência de hierarquias e papéis definidos aos quais os indivíduos devem se submeter, operando um processo de internalização de

\footnotetext{
${ }^{14}$ Original em francês: "Les instruments d'appréhension des realités politiques (et aussi des autres realités sociales) sont donc susceptibles d'être acquis tout au long de la vie, et le rapport à la politique (et plus généralement, au monde social) peut ainsi varier tout ao long de chaque histoire biographique. La socialisation doit donc être analysée comme um processus global coextensif à chaque histoire de vie."
} 
valores e regras que lhes influenciam a conduta. A ênfase nesse aspecto já estava presente no modelo goffmiano de "carreira moral", onde os processos de organizational modelling (os múltiplos efeitos socializantes do ativismo, em parte determinados pelas regras e modos de operação organizacionais, e que podem ser compreendidos como uma série de constrangimentos) ganham destaque (FILLIEULE, 2010). Como Gerth e Wright Mills observam, as instituições deixam sua marca nos atores que delas participam, influenciando tanto a sua conduta externa quanto a vida privada. Então, a partir da necessidade de examinar conteúdos e métodos de socialização dentro das organizações, Fillieule (ibidem) distingue e caracteriza três dimensões: a dimensão dos recursos, da ideologia, e as redes e identidades sociais.

No que diz respeito à dimensão dos recursos, o autor destaca a aquisição de know how e o desenvolvimento de uma sabedoria, adquiridos por meio da experiência no desempenho das funções exercidas e da ocupação de certos papéis. A dimensão da ideologia corresponde à internalização de regras e valores, que contribuem para a formação da visão de mundo dos partícipes da organização. Fillieule (2010) aponta que as organizações são governadas por regras escritas e tácitas, transmitindo hábitos e sistemas de crenças, que são incorporados pelos membros e pelas lideranças; e, de acordo com o autor, uma observação etnográfica das práticas ativistas cotidianas nos permitiria ver como as organizações legitimam certos tipos de discursos e práticas em detrimento de outros. Assim, as organizações desenvolvem as habilidades sociais e influenciam os perfis dos indivíduos que delas fazem parte, por exemplo, no que diz respeito aos estilos de comunicação, sobre os quais escreve Mische (2008). Compreendendo que as instituições funcionam de acordo com diferentes lógicas e que disciplinam as ações de seus participantes, ela chama de "estilos de comunicação" as práticas discursivas que se desenvolvem informadas pelos conteúdos institucionais. Assim, caberia ao indivíduo que atua em mais de uma organização a tarefa de construir pontes de mediação entre os diferentes locais de atuação. Por fim, considerar a dimensão das redes sociais e identidades consiste em atentar para as redes de sociabilidade e sua relação com a construção de identidades coletivas e individuais:

Em Tese, Florianópolis, v. 11, n. 2, jul./dez., 2014. ISSN: 1806-5023 
Acima de tudo, pertencer a uma organização é pertencer a um grupo, com suas bordas e mundo de significado, participando em sua illusio; é interagindo com outros membros, com níveis variáveis de regularidade; portanto, pertencer é construir um lugar ou uma identidade para si mesmo (FILLIEULE, 2010: 10 - itálico no original) ${ }^{15}$.

Trata-se, portanto, da construção de laços sociais e mesmo emocionais. A participação pode ser marcada pela renúncia (em relação a projetos e relacionamentos externos à organização) e pelo sentimento de comunhão, estimulado em reuniões, cerimônias e rituais, reforçando a identificação coletiva e o compromisso com o projeto ou causa em questão. Além disso, também ocorre a construção de laços afetivos, sendo que a existência de uma rede de sociabilidade desempenha um importante papel na manutenção do comprometimento com os objetivos da organização (seja por estímulo ou coerção). Nesse sentido, ao realizarem um estudo sobre o Levante Popular da Juventude, Silva e Ruskowski (2010) apontam as interelações sociais e o momento da "mística" - "espaço no qual a organização constrói seus símbolos identificadores e incentiva a continuidade da luta a partir da intensificação e expressão de sentimentos vivenciados no grupo" (ibidem: 44) - como elementos afetivos e emocionais fundamentais para o fortalecimento do engajamento militante, dado que promovem um "círculo de reconhecimento" no qual os projetos individuais se integram no projeto coletivo.

Tendo abordado elementos explicativos acerca das maneiras pelas quais o campo político, as experiências sociais e os processos de socialização desencadeados imprimem certas características nos indivíduos, passaremos agora às considerações finais.

\section{CONSIDERAÇÕES FINAIS}

\footnotetext{
${ }^{15}$ Original em inglês: "Above all, belonging to an organization is belonging to a group, with its borders and world of meaning, participating in its illusio; it is interacting with other members, with varying degrees of regularity; therefore, to belong is to construct a place or an identity for oneself".
} 
A partir do instrumental teórico apresentado, finalizaremos retomando e combinando as noções e conceitos vistos numa síntese útil ao estudo de carreiras de ativistas.

Se o que se pretende é abordar os itinerários de ativistas em termos das transformações (objetivas e subjetivas) por elas sofridos ao longo de sua carreira, levando a orientações e reorientações de seu fazer político, a utilização da abordagem da sociologia das carreiras militantes apresenta grande potencial instrumentalizador, uma vez que: a) divide e articula as dimensões objetiva e subjetiva da carreira; e b) combina, seguindo uma perspectiva interacionista, suas dinâmicas diacrônica e sincrônica, possibilitando compreender como os indivíduos, ao longo do curso de vida, interagem e são influenciados pelos (ao mesmo tempo em que influenciam) contextos e instituições onde se localizam.

Conjuntamente, partindo do entendimento de que a atuação política individual, apesar de dizer respeito ao campo político, não se encontra separada das outras áreas da vida pessoal, o emprego do conceito de esferas de vida, de Passy e Giugni (2000), mostra grande utilidade. Assim, cabe levar em consideração nas análises das carreiras a relação entre a esfera do ativismo e as demais esferas da vida: observar conexões, desconexões, conflitos e contradições entre as esferas, bem como seus impactos sobre o ativismo.

Por fim, a literatura mobilizada também permite considerar, de forma articulada com a abordagem das carreiras militantes, as influências: do campo político; das experiências sociais; e das socializações (particularmente, da socialização via participação organizacional) sobre os ativistas e suas carreiras - em suas dimensões objetiva e subjetiva. A abordagem desses elementos ajuda na apreensão dos efeitos da dimensão sincrônica sobre a dimensão diacrônica das carreiras, permitindo, dessa forma, apreender as transformações resultantes das mudanças de local de atuação e das posições ocupadas. 


\section{REFERÊNCIAS}

BALTAZAR, Bernadete. Quando a militância e a vida cotidiana se (des)encontram: Um estudo das concepções de lideranças sobre as relações do movimento popular com suas vidas. 1998. 195 f. Dissertação (Mestrado em Psicologia) - Universidade Federal do Espírito Santo, Vitória, 1998.

FILLIEULE, Olivier. Some Elements of an Interactionist Approach to Political Disengagement. Social Movement Studies, 2010, vol 9, $\mathrm{n}^{\circ}$ 1:1-15.

FILLIEULE, Olivier. Propuestas para un análisis procesual del compromiso individual. Intersticios - Revista Sociológica de Pensiamento Crítico. 2013, vol 7, n 1.

GAXIE, Daniel. Économie des partis et rétributions du militantisme. Revue Française de Science Politique. 1997, Volume 27, N. ${ }^{\circ} 1$, p. 123-154.

GAXIE, Daniel. Appréhensions du politique et mobilisations des expériences sociales. Revue Française de Science Politique. 2002, Vol. 52, n. ${ }^{\circ 2}$, p. 145-178.

GAXIE, Daniel. Rétributions du militantisme et paradoxes de 1'action collective. Swiss Political Science Review. 2005, 11 (1): 157-188.

KLATCH, Rebecca E. The Contradictory Effects of Work and Family on Political Activism. Qualitative Sociology, 2000, Vol. 23, No. 4, p. 505-519.

LERBACH, Brena Costa. A participação de lideranças oriundas de movimentos sociais no Estado: dinâmicas políticas, trânsitos e tensões. In: Terceira Jornada de Ciências Sociais da Universidade Federal de Juiz de Fora - UFJF, 2014, Juiz de Fora. Anais... Disponível em: <http://migre.me/p7C4m>. Acesso em: 22 de mar. 2015.

MISCHE, Ann. Partisan Publics: Communication and Contention across Brazilian Youth Activist Networks. Nova Jersey (EUA): Princeton University Press, 2008.

MORRIS, Aldon. Reflections on Social Movement Theory: Criticism and Proposals. Contemporary Sociology. 2000, Vol. 29, n. ${ }^{\circ} 3$, p. 445-454.

MORRIS, Aldon; STAGGENBORG, Suzanne. Leadership in Social Movements. In: SNOW, David; SOULE, Sarah A.; KRIESI, Hanspeter. (orgs.) The Blackwell Companion to Social Movements. MA, Oxford, Austrália: Blackwell Publishing, 2004.

PASSY, Florence; GIUGNI, Marco. Life-Spheres, Networks, and Sustained Participation in Social Movements: A Phenomenological Approach to Political Commitment. Sociological Forum, 2000, Vol. 15, No. 1, p. 117-144.

Em Tese, Florianópolis, v. 11, n. 2, jul./dez., 2014. ISSN: 1806-5023 
SILVA, Marcelo K.; RUSKOWSKI, Bianca de O. Levante juventude, juventude é prá lutar: redes interpessoais, esferas de vida e identidade na constituição do engajamento militante. Revista Brasileira de Ciência Política, n. ${ }^{\circ}$ 3. Brasília, janeiro-julho de 2010, pp. 23-48.

Em Tese, Florianópolis, v. 11, n. 2, jul./dez., 2014. ISSN: 1806-5023 


\title{
ABORDANDO ITINERÁRIOS DE ATIVISTAS A PARTIR DA SOCIOLOGIA DAS CARREIRAS MILITANTES
}

Resumo: Tendo como preocupação a busca por um instrumental teórico adequado ao estudo de trajetórias individuais de ativistas, este artigo apresenta a abordagem da sociologia das carreiras militantes como opção. Assim, seus principais pressupostos são apresentados de forma articulada com outros elementos e conceitos, dando relevo ao papel das esferas de vida, do campo político, das experiências pessoais e das socializações secundárias - em especial, as que acontecem dentro das organizações - na definição de posições individuais em relação ao engajamento e à política ao longo do curso de vida.

Palavras-chave: Ativismo. Engajamento político. Carreiras Militantes.

\section{APPROACHING ACTIVISTS' ITINERARIES BASED ON THE SOCIOLOGY OF ACTIVIST CAREERS}

\begin{abstract}
Concerning about the search for appropriate theoretical tools to the study of individual trajectories of activists, this article presents the approach of the sociology of activist careers as an option. Thus, its main assumptions are presented in coordination with other elements and concepts, giving prominence to the role of life spheres, the political field, personal experiences and secondary socialization - in particular those that take place within organizations - in the definition of individual positions regarding engagement and politics over the life course.
\end{abstract}

Keywords: Activism. Political engagement. Activist careers.

Recebido em: 09 de agosto de 2014

Aceito para publicação em: 23 de setembro de 2014

Em Tese, Florianópolis, v. 11, n. 2, jul./dez., 2014. ISSN: 1806-5023 